Revista de Psicología de la PUCP. Vol. XIV. No 2. 1996

\title{
DIDACTOPATOGENIA (Enfermedades generadas por la mala enseñanza)
}

\author{
Dr. José Cukier ${ }^{1}$ \\ Buenos Aires, Argentina
}

Se plantea el desarrollo de enfermedades generadas por la mala enseñanza. Se cuestiona el papel que cumplen las instituciones educativas al avalar a educadores con personalidad narcisista que inducen a estas enfermedades. Se describen las características de estos educadores, sus principales defensas y las interacciones didactopatogénicas que se establecen entre el educador y el educando, generando transformación pasivo/activo, tabú del pensamientos, saber enciclopédico, recuerdos póstumos, trastornos de conducta, distracción, y agresividad marcada. Se discute, también, el concepto del educador y sus dobles.

Palabras claves: enseñanza/aprendizaje, maestro, escuela, educación, didactopatogenia.

Didactopathogenicity

The author discusses the development of conditions generated by inappropriate teaching. The role of educational institutions that support educators with narcissistic personality is criticized. The characteristics of these type of educators, their main defenses and the didactopathogenic interactions that are established between the teachers and the students are described. These generate passive/active transformation, taboo thoughts, encyclopedic knowledge, posthumous memory, behavior disorders, lack of attention and marked aggressiveness. The concept of the teacher and his doubles is also discussed.

Key words: teaching/learning process, teacher, school, education, didactopathogeniciry

1. Es Presidente de la Sociedad argentina de Psicología Médica, Psicoanálisis y Medicina Psicosomática. Dirección: Dr. José Cukier Av. Santa Fe 2365-15 "H" (1123) Bs. As., Argentina. Internet: José\%jcukier@infod. ba.ar. 



\section{Introducción}

Estamos ante un sujeto en desarrollo, que debe conciliar las exigencias de la realidad, sus ideales y su vida pulsional, necesitado de modelos con los cuales identificarse. En este lugar estamos los educadores. No se trata de personas aisladas, sino que insertas en un contexto familiar, social, sufren del embate informativo, político y económico las más de las veces contradictorio. Se les pide por lo general aquello que desde los modelos se les niega. Deben ingresar en un mundo de cambios cada vez más acelerados. Se les pide prepararse para un tiempo futuro: el más incierto de los tiempos.

En el ejercicio de la asistencia psicoterapéutica de niños en edad escolar, he podido observar una serie de síntomas que tenían un origen en común. El agente desencadenante se encontraba en relación a determinados tipos de institución escolar y de educadores. Estos por la singularidad de sus características se constituyen en patogenizantes. Así puedo destacar una pléyade de síntomas que desarrollaré en el curso de éste ensayo, que pueden agruparse en tres áreas; trastornos psicosomáticos, de conducta y de aprendizaje por causa de la enseñanza inadecuada.

Puedo nombrar como ejemplo las hiperkinesias, descargas catárticas, espasmos bronquiales, dolores cólicos, gastritis, diarreas, insomnio, entre otros. A esta patología desencadenada por la mala enseńanza, propuse denominarla Didactogenia, como extensión del término médico iatrogenia. Consultada la Academia Argentina de Letras acerca de la validez del término, ésta respondió por carta del día 18 de Marzo de 1987 diciendo que “... a la patología inducida por la enseñanza puede denominársela "didactogenia" por extensión del significado comúnmente atribuido a la palabra iatrogenia. "Iatrogenia", del griego iatrós (médico), significa lo originado en el médico. 
El uso popular restringe el sentido al de la enfermedad producida por el médico ... en la voz consultada pueden reconocerse los formantes de procedencia griega, 'didacto' y 'genia'. El primero, apócope de 'didáctica', expresa la noción de 'proceso natural de formación' (de lo que se designa el formante inicial), como puede verse en las voces 'patogenia' o 'embriogenia' que aluden a la formación de la dolencia o del embrión respectivamente..." Desde el punto de vista morfo-etimológico, y sin considerar posibles situaciones de empleo 'didactogenia' aparece pues como un neologismo de cuño científico que, con la ambigüedad señalada, podría expresar la noción de lo originado por la enseñanza".

Como el término "Didactogenia" es abarcativo e incluye a todo lo que es originado en la enseñanza, prefiero la palabra "Didactopatogenia", para nominar a las influencias negativas producidas por la enseñanza inadecuada.

El marco referencial de éste trabajo se apoya en la teoría psicoanalítica, y el acento está puesto en la influencia que tiene el educador y las instituciones, como generadores de efectos positivos o negativos.

Pondré el énfasis en las modificaciones negativas que sufren las estructuras psicológicas de los educandos por la acción de los padres, educadores en general, líderes, la cultura y las instituciones, entre otras múltiples influencias.

Todas tienen efectos, y esto es preciso destacarlo, la mayor o menor intensidad depende del terreno diposicional previo y la tramitación que cada individuo le da. No obstante la influencia masiva o crónica de los factores ubicados en los desencadenantes actuales, pueden adquirir carácter traumático y de esta manera, desbordar las mejores disposiciones previas.

La enseñanza defectuosa es fuente, no sólo de trastornos caracterológicos, sino también de enfermedades somáticas. La mala pedagogía puede constituirse en un auténtico caldo de cultivo para las neurosis más diversas y debe fundarse sobre la comprensión y la eficacia y no sobre dogmas, (Ferenczi, 1908).

Cuando hablo de educadores, lo hago en sentido amplio. No me refiero al docente en particular, sino a todos aquellos que cumplimos con alguna función educadora. Los padres en primer lugar, la familia, los 
amigos, los maestros, el periodismo, los políticos entre muchos otros. Todos somos ubicados por los educandos en una posición en la cual, querramos o no, nos es asignado un saber y autoridad moral.

La buena enseñanza es sustancial para la prevención primaria, como que las condiciones culturales repercuten sobre las condiciones de salud.

En nuestra acelerada era tecnológica, la falta de la instalación de un vínculo en la relación entre el enseńante y el educando, que es organizador y estabilizante, reduce la transmisión del conocimiento a un acto eficientista y en escala industrial. Transformamos a los seres humanos en números y estadísticas disociados de los deseos y posibilidades de cada quién.

\section{Didactopatogenia inducida por la personalidad del educador narcisista. Concepto y generalidades}

Cuando el educador corresponde al tipo llamado narcisista tiene las siguientes características. Estas se centran en la arrogancia y la soberbia, en la convicción de estar por encima del educando. De ser el poseedor de la verdad, con poca capacidad de empatía y baja tolerancia a la frustración. Sentimientos secretos de triunfo, control y desprecio del educando. Escasa paciencia, curiosidad, creatividad y posibilidades lúdicas. Con más interés en conseguir el poder que el ascendiente. Este último depende de condiciones morales, en cambio el poder no implica necesariamente ascendiente y puede no tener connotaciones morales. Este poder en lugar de respeto, genera miedo en el educando, y provoca sometimiento o un simil de aceptación.

En la medida que no está discriminado el poder del ascendiente, podemos caer en el supuesto ideológico de que escuchar al educando es "dejarse manejar". Con este supuesto se avala la descalificación, porque ¿qué sentido tiene escuchar a quien no sabe? Finalmente, no queda margen para la sorpresa, el asombro, la duda, la inseguridad o el descubrimiento.

Este rasgo, cuando es dominante de la personalidad del educador, y avalado por un contexto rígido, puede inducir en el educando patologías, que son culturalmente aceptados como conflictos normales del estudiante. Se produce una normalización de la patología. Reitero que no me refiero al docente en particular, sino a una gran mayoría de personas que, en 
función educadora, podemos tener algún rásgo de éstos. Naturalmente no quedan excluidas las patologías psicopáticas y trastornos de aprendizaje propios del estudiante. Sólo intento llamar la atención acerca de otra posibilidad de lectura del problema.

\section{El psiquismo del educador narcisista}

La descripción que sigue, corresponde a un tipo ideal. Es preciso dejar en claro que las patologías son siempre mixtas, cambiantes, que algunas veces domina un aspecto, y otras veces otro distinto. El educador con rasgos dominantemente narcisistas tiene un conflicto básico. No tolera la realidad tal como es ni las diferencias. No tolera al educando, pero no por razones concientes de simpatía o antipatía, sino porque el estudiante es alguien, que con su presencia le marca al educador que hay otra persona autónoma diferente de él. Que tiene individualidad, pensamiento y voluntad propia. Esto hecho le pone límites a su omnipotencia y le marca la castración.

Pero esa presencia de otro diferente le genera hostilidad al educador, con sentimientos de aniquilación y de furia.

Desde ésta posición el educador narcisista trata de sostener la creencia de su omniciencia y genialidad. Intenta forzar esta ilusión que tiene de sí en el educando. Pero cuando éste mediante preguntas, lo desacredita, el educador se vuelve autoritario, para sostener su presunta grandiosidad. Habitualmente éste tipo de educador, le hace al estudiante lo sufrido pasivamente en activo. Podemos inferir un momento inicial en la infancia de éste educador en que sus preguntas eran selladas, por falta de respuesta a veces y otras por exceso. De ésta forma se interfería el interés, el desarrollo y la investigación. Quedaba con falta de comprensión, y entonces la realidad para ese niño, luego educador narcisista, perdía coherencia y no la entendía. Este fracaso marca un trauma en el psiquismo del educador que se mantiene y tiende a repetirse de manera compulsiva.

\section{El educador y sus dobles}

Habida cuenta de la necesidad del educador narcisista, de reencontrar en el mundo aquello que no sea traumático para su particular psiquismo, recurre al mecanismo de proyección de los "dobles", sobre las figuras de 
sus educandos (Freud, 1919), así alumno y educador no se diferencian. Consideramos los siguientes tipos de dobles:

- El doble imagen. En éste se privilegian los rasgos de la otra persona. Este doble apuntala la imagen del educador. Necesita que el educando a todo lo diga que sí. Cada acto del educando que arruina su imagen, le arruina la omnipotencia y le provoca sentimientos de vergüenza y humillación. Los alumnos le "hacen pasar vergüenza". Un ejemplo: el educador conoce superficialmente su tema y necesita dar una imagen de profundidad. Para ello intenta impactar como forma de ordenar que no le pregunten. Si le preguntan puede descalificar la pregunta o atacar porque se la hacen. $\mathrm{Da}$ un doble mensaje: "créanme porque sé en profundidad y a la vez desconfíen porque no sé responder a la pregunta, sólo la ataco". Puede inducir a la oligofrenización del otro: busca educandos a "su imagen y semejanza".

- El doble sombra. En el doble sombra se privilegian las expresiones faciales y los estados afectivos. La sombra, en el plano visual, tiene su correspondiente en el plano auditivo: los tonos de la voz. El educador está atento a la cara y a la voz de su interlocutor, más que a los contenidos del discurso de éste. Existe mayor descomplejización anímica cuando se privilegia la sombra respecto del predominio de la imagen, puesto que en ésta se rescatan los rasgos, que son discretos, distintivos, por sobre las expresiones. El educador proyecta su sombra afectiva en el educando y la lee en el rostro de éste. Cuando el educador pierde su función hace depositario de sus vivencias al estudiante, para que éste sea caja de resonancia de sus problemas. Un ejemplo: el docente que deliberadamente no le pone a su estudiante la nota merecida, sino más baja para "estimularlo". Le hace padecer a su doble los efectos sádicos de su superyo y crea una cara de tristeza. Un doble que nunca será reconocido y que padece lo mismo que su maestro. Es una sombra, o "un alma en pena" que sigue a su educador.

- El doble espiritual. El educador supone que la realidad es sólo réplica de una idea: sólo existen las ideas abstractas, que se descifran con una clave unificadora. Su discurso puede ser críptico, enigmático, y se aclara sólo cuando él comunica la clave que da coherencia y forma a lo que dice. A esta clave acceden los que están en comunión espiritual 
con él. Entiende que al educando hay que sacarle lo mejor, la esencia. Los recursos estilísticos que emplea tienen como meta sustraer a la realidad discursiva de aquello que la volvería compromiso vital. El lenguaje debe ser despojado, preciso, sin ornamentación. Constituye un laberinto descalificado en el cual el interlocutor se pierde. Para este educador, "lo esencial es invisible a los ojos". Estos rasgos son escenciales para la constitución de los guías espirituales de esos grupos o sectas de religiones exóticas, a las que suelen acudir los necesitados de un contexto que les garantice el sentimiento de ser y pertenecer.

- Doble orgánico. Este educador es por lo general una personalidad sobreadaptada y busca rendimientos a costa de procesos orgánicos propios del educando. Al descargarse en éstos, procura mantener su propia homeorrhesis (concepto de la biología, que alude a la homeostasis, pero no estática, sino con cierta direccionalidad, por ejemplo, hacia el crecimiento). Ofrece contenidos inadecuados al tiempo de aprender, generando estados de intoxicación en los estudiantes (semejantes a los que padece el educador). Los estudiantes suelen tener respuestas intelectuales adecuadas, a costa de la enfermedad orgánica. El educando, como doble que es, es transformado en "sangre de mi sangre" o "carne de mi carne". Si el educando se rebela, provoca el retorno del doble que el educador proyectó en el educando, y el maestro sufre la enfermedad psicosomática. Por ejemplo suelen decir que: "los alumnos me van a enfermar", "me matan de mala sangre", o que "salgo mareado de dar clases". Si el estudiante no estudia, le significa al educador una herida narcisista que busca ser restituida con mayores exigencias difíciles de cumplir y de efectos paradojales. Tal interacción produce en el estudiante síntomas de depresión, impotencia y pérdida de interés por la tarea compartida.

\section{Mecanismos de defensa del educador narcisista. Efectos somáticos en el educando}

\section{Desmentida}

Es una defensa universal que Freud, (1927, p. 150), considera que “... en modo alguno son raros en la vida infantil..." y que luego con la maduración desaparece. Se altera el juicio de la realidad exterior cuando 
ésta es traumática para el psiquismo. Se mantiene el registro perceptual, pero despojado de la representación "Verleugnung" y en su lugar, en el caso del educador narcisita, se lo sustituye por la representación del doble. Aquello que el psiquismo ha desmentido queda fuera del comercio asociativo de las ideas del educador, presto a volver como siniestro.

Cada educador tiene, o no, sus rasgos patológicos que le son singulares, cada cual tiene rasgos más o menos dominantes o formaciones mixtas, de combinaciones variadas. Como ejemplo de un educador narcisista tomaré el del educador con rasgos psicosomáticos y los efectos somáticos que su actuación es susceptible de producir en los educandos. Este concepto ha de tomarse también en un sentido extenso, como metafórico y evocativo de aquellas instituciones y políticas educativas o de otro orden, (económicas por ejemplo) que sólo tienen en cuenta el eficientismo y los resultados, no a las personas y el proceso de capacitación y aprendizaje

Las ganancias independientemente del costo psicofísico. La personalidad psicosomática se ubica como aquel que dice haberse creado solo, haber conquistado su lugar merced a un gran esfuerzo y que no le debe nada a nadie. Se ha hecho un nombre; en suma, es su propio padre. Procura hacerse un lugar, un prestigio.

El yo del educador psicosomático que desmiente puede a la vez expulsar un fragmento psíquico propio, sano, que está de acuerdo con la realidad y ubicarlo en un semejante. Cuando otra persona, por ejemplo un estudiante, es sensato y opera acorde con sus posibilidades y lo que le dicta su sentido común sin caer en el sobre esfuerzo, (no me refiero al esfuerzo sano y necesario para la conquista del conocimiento y de nuevas lógicas de pensamiento, sino a aquel que no tiene en cuenta el deseo propio y solo se somete al ajeno), el educador le atribuye a ese otro una actitud ingenua. Es un educando que "no se esfuerza", o no sabe "labrarse el futuro". Se ponen tan exigentes y persecutorios que generan retaliativamente, que desde la exterioridad les devuelvan la exigencia, y se sienten perseguidos. La tensión los mantiene estimulados y los convierte en educadores con alto nivel de exigencia, y que producen efectos paradojales. Sus educandos no rinden y contrariamente a lo que el consenso supone comúnmente, éstos educandos si tienen rasgos sanos, se van de la institución. 
Puede leerse ésta actitud como que "no se adaptaron" (lo cual es posible), pero también como que no se sobreadaptaron preservando su integridad psicofísica. Estos educadores suelen atentar contra la capacidad de autoconservación propia y ajena. A veces, por satisfacer la exigencia de terminar con un programa de estudios, a pesar de dificultades objetivas, tratan de satisfacer al ideal, de tal manera que se provocan y provocan en sus educandos excesos de cansancio induciendo de manera no explícita a la ingesta de estimulantes. Debido al padecimiento psicosomático, y al carácter calculador que los singulariza, tienen una retórica muy particular y se expresan en su discurso aludiendo a órganos y/o a números.

Es común observar frases como éstas: tal alumno es el "pulmón" o el "corazón" o el "riñón" de la clase. O el menos destacado, es conceptuado como un "cero a la izquierda". Expresiones comunes son: es un "alumno de diez puntos", "el hombre del millón de dólares", "la chica diez". Solo se acentúan los valores relacionados con los números mercenarios.

\section{Desestimación}

El educador refuta la realidad del educando, con la creencia de que éste es un transgresor. Este tipo de educador al no tomar nota de los requerimientos de sus estudiantes, continúa absorto en sus exposiciones y teorías, y en tal caso se da por supuesto que la falta de empatía con el educando deriva de que éste se halla sumido en un goce autoerótico. $\mathrm{Si}$ el alumno expresa una necesidad, sobrevendrá la furia del educador al ser sustraído de ese goce. Tomemos como ejemplo clínico un estudiante en la época de la latencia, en que evolutivamente se produce un empuje pulsional sin la posibilidad madurativa de descarga, (Freud, 1905), y ésta se traduce en actividad motora, en movimientos corporales. Ante un educador sobreexigente que no registra las necesidades del educando, aumenta más la tensión en el alumno, y ésta es decodificada como "actos de indisciplina". Los intentos de descarga frustrados pueden buscar su derivación por ejemplo vía toqueteo de los genitales, mal interpretada a veces como "masturbación compulsiva". Estamos ya en el camino de la patologización de un proceso normal. En un paso más surgen las descargas catárticas, gritos, espasmos de sollozos, dolores cólicos, (Freud, 1941). Por fin, y según las series complementarias de cada cual, unidos a los factores 
desencadenantes surgen las dermatitis y pruritos, vitiligo, alopecia areata, acné, exantema, eczemátide, biperhidrosis, dishidrosis, herpes simple y zoster, piodermia, reacciones alérgicas y asmáticas, (Koo, 1992; Van Maffaert, 1992). Expresión de una acumulación tensional que una mente en desarrollo no puede tramitar psíquicamente y que busca descargarse vía introyección orgánica. Otra forma de descarga es la autoagresión como por ejemplo escoriaciones, ulceraciones, onicofagia, entre otros. La expresión máxima de descarga tensional improcesable, tiene su manifestación en los accidentes. Una sola condición no es suficiente, como tampoco el becho puntual. Requiere además de la disposición previa del educando, de un medio familiar abandonante, de ciertas políticas educativas y de instituciones lideradas por educadores fascinantes.

\section{Contradicciones}

¿Cómo podemos producir, los educadores, efectos dañinos en la mente de los educandos, cuando domina en nosotros el fragmento narcisista. ¿Qué mecanismos ponemos en juego?

Para dar respuesta a éste interrogante, me voy a referir al tema de las contradicciones, (Maldavsky, 1986). En éstas hay una aceptación aparente de las normas consensuales, pero de hecho, ya sea través del discurso o de actos, estas normas son en verdad cuestionadas. Suelen decir una cosa y hacer otra, o decir cosas opuestas simultaneamente. Tiene vigencia aquello de "haz lo que yo digo pero no lo que yo hago". Podemos considerar los siguientes tipos de contradicciones.

a. Contradicción orgánica: Suele darse en educadores hiperactivos, exigentes y sobreadapatados, (Maldavsky, 1986). Nunca se cansan, o mejor dicho no hay registro del cansancio propio ni ajeno. Hasta que súbitamente se enferman somáticamente. $O$ inducen a la enfermedad del estudiante y de esta manera se sostienen en un equilibrio precario a costa de la descarga en una mente ajena. Este tipo de educadores cuanto mayor es la tensión a la que se someten, mejor se sienten, y mayor es el esfuerzo por aumentarla. Hay contradicción entre el llamado corporal a la suspensión del sobreesfuerzo vía síntoma, y la promesa ilusoria de mayores triunfos y goces si continúa. Contradicción entre autoconservación y narcisismo. $\mathrm{Y}$ esto es lo que piden 
también de sus estudiantes sin tomar en cuenta el tiempo de aprender y con ello coartan la posibilidad de comprensión. Producen intoxicación. Hay un esfuerzo por aumentar cada vez más los rendimientos, y no toleran ningún cuestionamiento. Se acompaña de prohibición de toda queja u oposición. Pero además el educador siente la amenaza de depresión y vacío si disminuye la intensidad de su accionar o si fuga del campo. Vale lo mismo para el educando. Y otra cosa más, hay una promesa ilusoria de mayor placer creciente si se mantiene la actividad, que en realidad ubica al educador y al educando al borde del colapso somático.

b. Contradicción lógica: Hay una oposición entre una afirmación específica y una más amplia. Contradicción entre dos registros perceptuales, por ejemplo lo visto y lo oído por el educando. Cuando el educador da un mensaje desde el discurso o desde sus actos y a la vez los desmiente. Entonces surge la duda: ¿dónde está la verdad? ¿a quién se le debe creer? ¿no es que al educador hay que creerle, entonces...? $\mathrm{O}$ bien órdenes opuestas entre el educador y el contexto, lo que muestra la realidad y lo que dicen los medios de difusión. ¿A quién creerle? Se puede reforzar con un impedimiento a cuestionar la contradicción. Para ello se puede poner en práctica el recurso más sencillo de hacer callar al interlocutor, a partir del uso autoritario de la posición asimétrica entre el educador y el educando. Otra medida más sofisticada, consiste en el desvío del pensamiento. En éste recurso hay una aparente respuesta a la pregunta que pudiera hacer el educando, pero en realidad se lo desvía hacia otro tema. En la contradicción lógica, ambos términos contradictorios están presentes, y es posible contrastar la contradicción. Sin embargo, a veces, un término se presenta bajo la forma de un recuerdo de una frase dicha en otra oportunidad y opuesta a lo dicho actualmente. $O$ hay oposición entre lo dicho por el educador y el mensaje que puede dar en los hechos, a través de algún gesto o de actos que lo contradicen. Por ejemplo proclamar la honestidad y protagonizar hechos corruptos. $\mathrm{O}$ contradicción entre las normas morales que pueden enseñarse a los estudiantes, y las que verdaderamente se ponen en práctica en privado, o públicamente.

c. Contradicción semántica: Se afirma experimentar un afecto o un deseo, pero la actitud correlativa es opuesta a lo que se afirma. Por ejemplo, "te ordeno que seas feliz". Son exigencias que imponen una sanción 
al incumplimiento y el que exige, sufre si el exigido defrauda el anhelo del primero. El castigo es inocular culpa por el incumplimiento. Con ello el que ordena queda en la posición de víctima y ésta en la posición de victimario, con lo cual se induce la confusión.

d. Contradicción pragmática: Son órdenes contradictorias, paradojales que se refuerzan en el ambiente con otras dos órdenes: prohibición del comentario, prohibición de alejarse del campo. Claro que no es el hecho puntual el patogenizante sino su reiteración y la imposibilidad de refutar o huir. Por fin todos estos mecanismos, pueden ser reforzados con discursos demagógicos y fascinantes, que apelan a los afectos y a la adhesión al líder. Con ello tratan de convencer de la "irracionalidad" de creer en lo que se ve, de creer en los sentimientos o en la forma de pensar convencional. Solo se debe creer al líder, que es el dueño de la verdad.

\section{La acción didactopatogénica. Conceptos generales}

Los educadores con rasgos narcisistas, a veces ponen o ¿ponemos? en juego estos mecanismos descritos e intentan o ¿intentamos? que el educando los padezca. Si el educando no se rebela ante el educador, el educando termina por dudar de lo que ve o de lo que oye. La realidad se le hace extraña. El educando puede, según su disposición previa, llegar al recurso último de desestimar la realidad. Si el educando sí se rebela, obliga al educador a rectificarse, o si el educador reitera su posición y no se doblega ante la contundencia de la realidad, recurre a la defensa radical de desestimar. En ésta interacción generada por las contradicciones, desmentidas y desestimaciones, el educando es objeto de una violencia mayor que la autoritaria. En la violencia autoritaria, se hace callar al otro, pero este otro mantiene la capacidad de pensar. En cambio con la desmentida, la desestimación y las contradicciones, operando sobre un psiquismo en desarrollo puede imposibilitarse la posibilidad de pensar, Y con ello arrancarle al educando la convicción. Convencerlo de que son verdades las mentiras, a pesar de que su sentido común y capacidad de deducción le dicen lo contrario. Convencerlo de que lo que ve no es lo que ve. Desconfiar de sus registros perceptuales y de sus sentimientos. El educando corre riesgos cuando este tipo de educador sostiene reiteradamente estos mecanismos. Pero una sola condición no es suficiente. Requiere además, de 
la disposición previa del educando, de un medio familiar abandonante, de ciertas políticas educativas y de instituciones rígidas lideradas por educadores fascinantes. Este sistema pone al educando en riesgo de oligofrenizarlo porque no puede pasar al pensar activo, sino que permanece pasivo ante el pensar del educador. Hay riesgo de enloquecerlo cuando el contexto avala que la realidad sensorial es diferente al registro perceptual del educando. El efecto didactopatogénico se instala, no por la contradicción, sino por la imposibilidad de cuestionarla o de huir. Tampoco se instala la patología por la acción de hechos puntuales, sino de procesos que tienen un despliegue temporal y en determinada época de la vida. Cuanto más precoz es más efectiva la actividad didactopatogénica. Se van dando las condiciones desde la temprana mala enseñanza para la indefensión intelectual y la desesperanza, disminución del interés en la participación colectiva, interés en la vida y en la lucha por ésta, desamparo infantil por no estar el educando incluido como un Ser en la mente ajena, falta de autonomía para bastarse a sí mismo en forma adaptada a las normas consensuales. Se va, de manera inconciente e insensible, sellando el futuro del niño.

\section{Las interacciones didactopatogénicas. Sus manifestaciones}

Cuando el educador narcisista desmiente la realidad psíquica del educando, no reconoce los distintos tipos de pensamiento de éste, acordes con cada período evolutivo del estudiante. También desmiente el educador las diferencias de cada uno de los educandos entre sí, en qué situación se encuentra cada cual.

Algunos estudiantes han llegado al nivel de pensamiento que la institución escolar y el educador esperan de ellos. Otros no han llegado. Cuando institución y educador desconocen las diferencias que los estudiantes tiene entre sí, imparten una enseñanza aparentemente igualitaria: a todos los educandos la misma enseñanza. Pero el efecto que produce es paradojal, acentúa las desigualdades de los educandos entre sí y de los educandos con el educador. Las desigualdades de los estudiantes entre sí se acentúan porque estudiantes de distintos niveles de evolución en su pensamiento reciben idéntica información. Entonces el estudiante de nivel más evolucionado puede recibir información insuficiente y queda carente de estímulo. Puede distraer su energía disponible para el estudio a través 
de la descarga en la acción generando "trastornos de conducta". El alumno de nivel menos evolucionado puede recibir información que aún no puede comprender, puede generar supuestos "retrasos mentales".

La trasformación pasivolactivo. El incansable preguntar del infante que tan enigmático parece a los adultos, es porque estos no se dan cuenta que todas estas preguntas solo son rodeos alrededor de una cuestión central. La investigación recae sobre el origen de los niños (Freud, 1910). El niño rehusa creer los datos que sobre ésta materia le suelen ser proporcionados. Por más que los padres le den buenas respuestas desde su perspectiva, el niño igual no cree y este descreer, inicia su independencia intelectual. El niño no cree porque su maduración psíquica aún no está completada para entender. Es un fracaso universal, incitante para seguir pensando, es el prototipo de toda labor intelectual. Este fracaso universal, necesario, no contingente, parece ser además una marca fundamental para el ulterior desarrollo de la cultura humana. Otro tipo de desautorización tiene que ver con mantener la ilusión que está al servicio de defenderse del displacer. El niño no quiere escuchar para cuidar ilusoriamente su omniciencia.

Está en condiciones de creer, pero no tolera lo que dicen. Es una defensa universah una actitud hostil frente a la palabra oída del padre. Cuando aparece la tendencia a desautorizar la palabra oída, a pesar de ser valedera, suele ocurrir que los padres tengan una actitud desautorizante ante su propia palabra. Desautorización de los padres entre sí; desautorización del padre, de una función como padre insuficientemente desarrollada; desautorización desde la función de su propia palabra, por ejemplo: "haz lo que yo digo pero no lo que yo hago". En ésta frase, su propia palabra queda desautorizada por su hacer. Así se constituye un núcleo didactopatogénico en el educando, que luego se repite activamente. En la didactopatogenia el fracaso deriva del insuficiente vinculo con los padres. Es necesario distinguir los dos tipos de fracaso. El primero es estimulante; el segundo tipo de frustración está ligado a la arrogancia de los padres y educadores, interfiere las preguntas, su desarrollo y la investigación.

Imperativos categóricos. Tabú del pensar. Saber enciclopédico. Recuerdos póstumos. Otras consecuencias. Un educador sabe que, en un comienzo, su discurso es escuchado por el educando como un imperativo categórico. Tales 
imperativos son universales, incondicionales. Este imperativo se sintetiza en una fórmula, ésta impone obrar de tal modo que se pueda desear que el motivo que rige ese deseo de obrar sea una ley universal. Ante estos imperativos el yo carece de capacidad analítica crítica. El imperativo abarca el terreno de la sexualidad, el del trabajo y el de la muerte. En el plano de la sexualidad, una serie de órdenes prohiben la masturbación, imponen la necesidad de la maternidad o la paternidad. En el plano laboral la orden podría definirse como "ganarás el pan con el sudor de tu frente", y en cuanto a la relación con la muerte, la orden consiste en reconocer la necesidad del fin de la vida personal. Inferimos que se trata de órdenes porque ante cada uno de estas situaciones el yo reacciona con una actitud desafiante, que es un modo de acatamiento de la ley como por ejemplo: por qué me tengo que morir, por qué tengo que trabajar, o engendrar hijos. Progresivamente con la maduración neuropsicológica y la explicación pertinente adecuada al momento evolutivo de la mente infantil, el niño va comprendiendo las razones. Cuando se interfiere la conquista de esas razones, por falla en la respuesta (por déficit o por exceso de la misma) los imperativos se mantienen como tales. Con ello la dependencia del educando y perpetuación del poder del educador. El natural deseo de saber infantil, puede encontrarse con la prohibición externa para el pensar. Frente a la misma se instala el tabú del pensar. Al interrogante que formulan los niños se le interponen un saber enciclopédico ya constituido que obtura los interrogantes. Pueden reprimirse los interrogantes y rellenarse con conocimientos enciclopédicos que inducen a la memorización y la repetición. Las respuestas inadecuadas al momento evolutivo pueden quedar inscriptas como recuerdos póstumos. Esto significa que la información no puede ser asimilada hasta ser articulada con la vivencia y devenir en comprensión. En estos casos el educador puede entender que la no comprensión del educando es por "déficit del aprendizaje o error del educando".

Toda vez que el interrogante es obturado, se evita la interacción, la toma de decisiones y la autonomía consiguiente. La desmentida del educador, conjuntamente con la desmentida de la institución educativa y sostenida por programas de estudio inadecuados, puede inducir a la desestimación por parte del alumno. Esta desestimación puede manifestarse como trastorno de conducta, distracción, agresividad marcada, sexualidad exacerbada. Cuando se detectan estos síntomas, suelen evaluarse 
como trastorno individual del educando (que puede serlo), pero desmientiendo una vez más el efecto didactopatogénico de este tipo de enseñanza.

Otras consecuencias. La escisión del yo del educando y sus derivados. En la mente infantil, la desmentida y consiguiente esciión del yo no es patógena hasta cierto momento del desarrollo (Freud, 1927). Esta escisión le sirve al educando para mantenerse en el autoerotismo y como resistencia para adecuarse a la cultura. La tenaz adherencia a las fuentes de placer disponibles y la dificultad de renunciar a ellas parecen constituir una tendencia general de nuestro aparato anímico. Con la instauración del principio de la realidad, enseñanza mediante, queda disociada una cierta actividad mental que permanece libre de toda confrontación con la realidad y sometida exclusivamente al principio del placer. La acción continuada del autoerotismo permite que la satisfacción de objetos imaginarios, más fácil y pronta, sea mantenida en sustitución de la satisfacción en objetos reales, que es más trabajosa. Al sostenerse desde la mala enseñanza la escisión, una parte del yo se relaciona con el educador como si comprendiera, y otra se conecta con los objetos imaginarios. Cuando el educador mantiene o estimula la escisión con mensajes inadecuados a las lógicas en juego del educando, el yo de realidad de este no aprende porque no vivencia; ésta se encuentra afectada al deseo. Sin vivencia no hay huella mnémica, sólo seudoaprendizaje y memorización. Se predispone el terreno a las trasgresiones éticas (porque el yo no asimila las normas consensuales, solo las imita, y otra parte del yo, solo atenta a la satisfacción, trasgrede). Unidas a otras precondiciones como las fijaciones en el desarrollo psicosexual, la acción sobrestimulante de contextos inductores, modelos parentales adictivos, se instalan las adicciones y las conductas perversas, legalizadas desde la autoridad del enseñante. Cuando la enseñanza es contraria a las lógicas en juego del educando, el yo de realidad de éste intenta defenderse y se distrae. Se producen falsos intercambios con acumulación de información inmodificada. Se afecta la capacidad de pensar. El educando organiza un seudoconocimiento sobreadaptándose, con excesiva dedicación de tiempo para el logro de sus objetivos. Los rendimientos no están acordes con el esfuerzo demandado, se instala el desinterés por la tarea, déficit de la formación y de autonomía psíquica. La sobreadaptación se acompaña de la sofocación de los deseos propios en función de adaptarse a los deseos del otro. Esto despierta odio 
y desesperación, afectos que buscan su descarga por la vía motora y o en el insomnio. La falta del dormir ocasiona un estado confusional con pérdida de la memoria y momentos transitorios de desorganización mental. El educador, avalado por instituciones y políticas educativas que desconocen al educando, puede reproducir masivamente la inducción de patologías didactopatogenizantes. Asistimos a la "clonación". Es decir, reproducción indiferenciada de "sujetos", idénticos entre sí y réplicas del modelo ideal que propone la institución y el educador. Sin embargo un educando necesita del educador. Lo busca porque hay algo de la pulsión, no enteramente satisfecho que insiste reiteradamente, Insiste y mantiene abierto los interrogantes buscando un camino que el educador puede ayudar a satisfacer en parte.

\section{De la didactopatogenia a la violencia social}

Esta particular manera de seudorrelación del educador con el educando, es la antítesis de amar, entendida como incluir al semejante. Es ignorar, marginar, exiliar, dejar afuera, desconocer. El niño aunque fácticamente pertenece a una familia, un grupo o una sociedad, intrapsíquicamente se siente carente de atribución y pertenencia (Puget et al., 1993). La falta de reconocimiento lo incapacita para adquirir la adecuada inserción en la escuela, el barrio, el grupo religioso, la etnia o el país que le toca vivir. $\mathrm{El}$ reconocimiento proveniente de un otro, que los educadores en sentido ampliado lo acepten, el país como ciudadano, el grupo religioso como miembro, que todos y cada uno lo confirmen, contribuye a la construcción de la identidad. Las fallas de los mecanismos de atribución por parte de los educadores generan las ansiedades de no pertenencia y amenaza de ser ignorado, excluido o marginado. El nińo completa su maduración en el vínculo con los Otros entendidos como el conjunto de los semejantes que integran una comunidad, y ésta imprime un sello propio a la mente infantil

No es posible sustraerse de la estructura social en la que estamos inmersos. Cada espacio deja marcas fundantes distintas, tanto más intensas cuanto mayor la ascendencia del espacio influyente, más precoz el desarrollo evolutivo en un encuentro con las disposiciones genéticas, hereditarias y familiares de cada cual. Cada espacio tiene sus reglas de funcionamiento y valores imperantes, cuyo pilar básico es la conservación de la 
vida. El anhelo de ocupar un lugar se liga a las injurias de la autoestima originadas en la temprana exclusión de pertenecer. Se ponen en marcha los mecanismos de la pugna interrelacional siempre latentes, necesidad imperiosa de ganar "a toda costa". La adherencia acrítica a modas y grupos, conductas ritualizadas, modalidades imitativas defensivas para neutralizar sentimientos de inermidad. Maniobras trepadoras, actitudes manipuladoras, rasgos trasgresores y corruptos para llegar al extremo del terror social conductas racistas y fanáticas, son algunos de los recursos que la viscicitud patógena de la enseńanza provoca sobre la necesidad del infante humano de pertenencia.

\section{Referencias}

Ferenczi, S. (1908). Primer Congreso Psicoanalítico Internacional Salzburgo. Freud, S. (1905). Tres ensayos de teoría sexual A.E. S.E. 7.

Freud, S. (1910). Un recuerdo infantil de Leonardo da Vinci. A.E. 23 S.E, 11.

Freud, S. (1912-13). Totem y tabui A.E. 12 S.E.13

Freud, S. (1914). Sobre la psicologia del colegial A.E 13 S.E.4

Freud, S. (1917). Un recuerdo de infancia en Poesia y verdad. A.E.17 S.E. 17

Freud, S. (1918). El tabú de la virginidad (Contribuciones a la psicologia del amor. III) A.E. 17 S.E. 11.

Freud, S. (1919). Lo ominoso, A.E. 17 S.E.17.

Freud, S. (1927). Fetichismo, A.E. 21 S.E. 21.

Freud, S. (1939). Moisés y la religión monoteista A.E. 23 S.E. 23

Koo, John J.M. (1992). Psychodermatology Arch. Dermatol. V 128.

Lazarus, R.; Folkman, S. (1986). Estrés y procesos cognitivos. Barcelona: Martínez Roca.

Maldavsky, (1986). Estructuras narcisistas. Constitución y transformaciones. Buenos Aires: Amorrortu.

Maldavsky, (1991) Procesos y estructuras vinculares. Buenos Aires: Nueva Visión.

Piaget, J. (1942). Psicologia de la inteligencia. Buenos Aires: Psique.

Piaget, J. (1957). Logic and Psychology. Nueva York: Basic Books.

Piaget, J. (1959). La formación del simbolo en el niño. México: Fondo de Cultura Económica. 
Puget, J., Bianchedi, E., Braun, J. y Pelento M. L. (1993). Status psicoanalítico de la violencia social. Rev. de Psicoanálisis. T L. N 4/5.

Van Moffaert, (1992). Psychodermatology: An Overview. Psychoterapy. Psychosom. 58. 125-136. 